\title{
INTERFERÊNCIA DAS PLANTAS DANINHAS SOBRE ALGUMAS CARACTERÍSTICAS AGRONÔMICAS E A PRODUTIVIDADE DE SETE CULTIVARES DE MILHO ${ }^{1}$
}

\author{
IVAN H. ROSSI ${ }^{2}$, JUAN A. OSUNA ${ }^{\text {s }}$, PEDRO L.C.A.ALVES ${ }^{4}$ e ALEXANDRE J. BEZUTTE ${ }^{5}$
}

\section{RESUMO}

O presente trabalho teve por objetivo estudar o comportamento de 7 cultivares de milho (Zea mays L.) quanto à interferência da comunidade de plantas daninhas. Para tanto, os 7 cultivares de milho (ESALQ VF-7, ESALQ VD-8, COMPOSTOS ARQUITETURA, FLINT e DENT ADO, PIRANÃO e o híbrido CARGILL 501) foram submetidos a duas condições de int er fe rên cia: com e sem, totalizand o 14 tratamentos arranjados em esquema fatorial (7x2), instalados, no campo, em área experimental da FCAV/UNESP, Campus de Jaboticabal, seguindo o delineamento experimental de blocos ao acaso com 4 repetições. A comunidade infestante cujas espécies mais importantes foram SIDCO, BRAPL e ELEIN, estabeleceu -se a partir dos 14 dias após a semeadura, passando a interferir negativamente sobre a cultura a partir dos 35 dias. Os cultivares
$\mathrm{CD}$ e $\mathrm{CF}$ apresentaram maior crescimento que os demais. A interferência da comunidade infestante reduziu a altura de inserção da primeira espiga; o comprimento e a circunferên cia das es pigas, os pesos da espigas e dos grãos e a produção estimada da cultura, independente do cultivar. Os cultivares PIR e ARQ, independente da interferência, mostraram-se os menos produtivos. O cultivar Carg mostrou-se

o mais produtivo mesmo quando sob interferên cia. O cultivar ARQ foi o ma is sen sível à interferência, enquan to PIR e VF-7 foram os menos sensíveis, podendo ser utilizados em programas de melhoramento genético visando tol erância a interferência de plantas daninhas.

Pal av ras ch ave: Ze a mays, pl an ta daninha, matointerferência.

\section{ABSTRACT}

\section{Weed interference in seven corn cultivars.}

The present work had as an objective to study the behavior of seven corn cultivars, according to the interference of weed plants. So that, the seven corn cultivars (ESALQ VF-7, ESALQ VF-8, COMPOSTOS ARQUITETURA, FLINT E DENTADO, PIRANÃO and CARGILL 501) were submitted to 2 kinds of interference; with an without, totalizing fourteen treatments organized in a factorial plan $(7 \times 2)$, installed in the field as a experimental design of casual blocks with four replications. The infest community, that the most important species were SIDCO, BRAPL and ELEIN, already established fourteen days after the sowing, beginning competition after thirty five days. The cultivars $\mathrm{CD}$ and $\mathrm{CF}$ presented a higher plant height than the othercultivars. The weed interference decreased the weight of grain and ear yield, the ear length

\footnotetext{
1 Recebido para publicação em 29/05/96 e na forma revisada em 23/08/96.

2 Eng. ${ }^{\circ}$. Agr ${ }^{\circ}$. estagiário do Depto de Biologia Aplicada a Agropecuária da FCAVJ/UNESP.

3 Prof. Titular do Depto de Biologia Aplicada a Agropecuária da FCAVJIUNESP.

4 Prof. Assistente do Depto de Biologia Aplicada a Agropecuária da FCAVJ/UNESP.

5 Aluno de Pós-graduação, Depto d e Biologia Aplicada a Agropecuária da FCAVJ/UNESP, Rod. Carlos Tonnani, Km 05, CEP 14.870-000, Jaboticabal - SP.
} 
and circumference and the distance from the soil to first ear. The cultivars PIR and ARQ independent of the interference, showed to be the less producible. The cultivar CARG showed to be the most producible, even when with weed interference. The cultivar ARQ was the most

\section{INTRODUÇÃO}

O milho é a principal cultura agrícola brasileira, com produção total de grãos de aproximadamente 25 milhões de toneladas. Nossa contribuição mundial é, porém, ainda bem inferior à dos países mais produtivos, o que é devido principalmente a baixa produtividade (Ramos, 1992).

A cultura de milho, apesar de ser considerada como de boa capacidade competitiva (Heemst, 1986) e ser enquadrada entre o grupo de culturas que mais sombreiam o solo (Keeley \& Thullen, 1978), sofre intensa interferência das plantas daninhas, com sérios prejuízos no crescimento, na produtividade e na operacionalização de colheita (Ramos, 1992; Viswanath, 1977). Portanto, reduzir ou eliminar esta interferência consiste numa prática indispensável à produção de milho.

Uma forma de reduzir os custos de produção é a utilização de cultivares de milho que competem mais efetivamente com as plantas daninhas pelos recursos do meio. Isto, pode ser alcançado buscando-se plantas com características de arquitetura que podem limitar a penetração de luz ao nível do solo, como altura, folhas largas e grande número de folhas orientadas horizontalmente (Ford \& Pleasant, 1994). Reduzindo a incidência de luz na superfície do solo, haverá decréscimo na germinação de algumas espécies de plantas daninhas e no crescimento das plântulas (Duke, 1985). Contudo, são poucos os estudos comparando a competitividade entre cultivares de milho e destes com plantas daninhas. Em virtude do relatado, objetivou-se neste trabalho, avaliar o desenvolvimento e a produtividade de sete sensitive in relation to the interference, while PIR and VF-7 were the less, showing that these cultivars present potentiality to be used in a ge ne tic improve program, aiming tolerance to weed plants interference.

Key words: Zea mays, weed competition.

cultivares de milho quando submetidos à interferência de uma comunidade de plantas daninhas.

\section{MATERIAL E MÉTODOS}

Este trabalho foi conduzido sob condições de campo, no município de Jaboticabal (SP), num Lato ss ol o Vermelho Escuro, text ura média, distrófico, A moderado e de classe textural argilosa. Antes da instalação, o solo foi amostrado e de acordo com a análise química $\left(\mathrm{P}_{\mathrm{res}}\right.$ $=19 \mu \mathrm{g} / \mathrm{ml} ;$ M.O. $=2,3 \% ; \mathrm{PH} \mathrm{CaCl} 2=4,7 ; \mathrm{K}=$ $0,37 \mathrm{meq} / 100 \mathrm{ml}, \mathrm{Ca}=1,6 \mathrm{meq} / 100 \mathrm{ml} ; \mathrm{Mg}=$ $0,8 \mathrm{meq} / 100 \mathrm{ml} ; \mathrm{H}+\mathrm{Al}=3,4 \mathrm{meq} / 100 \mathrm{ml} ; \mathrm{SB}=$ $2,77 \mathrm{meq} / 100 \mathrm{ml} ; \mathrm{T}=6,17 \mathrm{meq} / 100 \mathrm{ml} ; \mathrm{V}=45 \%$ ), efetuou-se a sua correção. O preparo do solo adotado foi o convencional, com uma aração e duas gradagens, sendo que antes da aração foi adicionado calcário dolomítico em quantidade equivalente a $2,5 \mathrm{t} / \mathrm{ha}$.

A semeadura foi realizada no dia 12 de outubro de 1992, e o espaçamento adotado foi de 0,90 ni de entre-linhas e as sementes espaçadas entre si em $0,20 \mathrm{~m}$. Na ocasião da semeadura adicionou -se $200 \mathrm{~kg} / \mathrm{ha}$ do adubo formulado 43010 e 45 dias após realizou -se adubação de cobertura adicionando-se $300 \mathrm{~kg} / \mathrm{ha}$ de sulfato de amônio, quando as plantas de milho encontravam-se com 6-7 folhas.

Os tratamentos experimentais foram compostos por sete cultivares: ESALQ VF-7 (VF7) e ESALQ VD-8 (VD-8), de porte médio e ciclo sem iprecoce; COMPOSTO ARQUITETURA (ARQ), de folhas eretas, porte pequeno e ciclo semi precoce; HÍB RID O CARGILL - 501 (CARG), híbrido duplo do tipo meio dente, de porte médio e ciclo precoce; PIRANÃO (PIR), de 
porte baixo e ciclo normal; COMPOSTO DENTADO VII (CD), de porte alto e ciclo tardio e COMPOSTO FLINT VIII (CF), de porte alto e ciclo tardio, submetidos a duas condições de interferência das plantas daninhas (com e sem), totalizando 14 tratamentos. A condição sem interferência das plantas daninhas foi obtida mediante capinas manuais periódicas nas parcelas correspondentes.

No campo, os tratamentos experimentais foram locados segundo o delineamento de blocos ao acaso, com quatro repetições e os tratamentos foram dispostos em esquema fatorial 7 × 2 , onde constituíram variáveis principais as sete cultivares de milho e as duas condições de interferência, totalizando 56 parcelas. As parcelas experimentais apresentaram cinco linhas de semeadura e cinco metros de comprimento cada, perfazendo uma área de $22,5 \mathrm{~m}^{2}$. Como área útil, considerou-se as três linhas centrais, desprezando-se $0,5 \mathrm{~m}$ das extremidades, totalizando $10,80 \mathrm{~m}^{2}$.

Em intervalos quinzenais, da semeadura até a colheita do milho, avaliou-se a comunidade infestante através de duas sub-amostragens de $0,25 \mathrm{~m}^{2}$ cada, onde realizou-se a contagem e a identificação dos indivíduos. Aos 154 dias após a semeadura do milho, as plantas daninhas presentes na área amostral foram colhidas, separadas por espécie, contadas, postas a secar em estufa de circulação forçada de ar $\left(70-80^{\circ} \mathrm{C}\right)$ e, posteriormente, pesadas. Concomitantemente às av al iações de densidade, for am realizad as avaliações visuais de cobertura do solo pela comunidade infestante, segundo a escala de notas da ALAM, 1974.

Por acasião das avaliações da comunidade infestante, avaliaram-se nas plantas de milho: altura e área foliar (obtida através do produto do comprimento total das folhas pela largura média destas e pelo fator de correção 0,75 definido por Carleton \& Foote (1975) para o milho). Posteriormente, a planta foi separada em suas diferentes partes (colmo e folhas que foram separadas em lâminas e bainhas), e foram postas para secar em estufa com circulação forçada de ar $\left(70-80^{\circ} \mathrm{C}\right)$ para a obtenção dos pesos da matéria sec a. Pa ra a aval iação da sa racterís tica s agr onômic as, da produtividade e da produção estimada, foram levantados os seguintes parâmetros: altura das plantas e altura de inserção da espiga principal, para as quais foram escolhidas 10 plantas por parcela; número de plantas por metro linear (estande); porcentagem de plantas ac amadas; número de es pi gas por planta; porcentage m de espigas danificadas por Helicoverpa zea; comprimento da espiga; comprimento da palha; número de fileiras de grãos por espiga; circunferência da es pi ga; compactação da palha; peso total das espigas por planta; peso dos grãos; peso médio por espiga e produção (estimada através do estande final e do peso total de grãos por planta).

Os dados obtidos foram submetidos a análise de variância pelo teste $\mathrm{F}$ e as médias comparadas pe lo teste de Tukey a $5 \%$ de probabilidade.

\section{RESULTADOS}

No transcorrer do período experimental, constatou-se que ocorreram 25 espécies de plantas daninhas na área experimental. Houve predomin ância de di cotile dône as, com 17 espécies, representando $68 \%$ na composição da flora encontrada. Em termos de família, a mais numerosa, ou seja, aquela com mai or rique za florística dentre as encontradas, foi a Poaceae, com 6 espécies, seguida pela Asteraceae, com 4 espécie. Estes resultados confirmam o inventário florístico de comunidades de plantas daninhas no Estado de São Paulo realizado por Blanco \&

Santos (1988). De ntre as plantas daninhas encontradas, as 12 espécies mais importantes visualmente, estão relacionadas na Tabela 1 , com se us respectivos códigos in ternaciona is de identificação adotados pela Internacional Weed Science Society, família e classe a qual pertencem. 


\begin{tabular}{lccc}
\hline \multicolumn{1}{c}{ Espécie } & Código & Familia & Classe \\
\hline Amaranthus retroflexus & AMARE & Amaranthaceae & Dicotiledônea \\
Bidens pilosa & BIDPI & Asteraceae & Dicotiledônea \\
Brachiaria plantaginea & BRAPL & Poaceae & Monocotiledônea \\
Cenchrus echinatus & CCHEC & Poaceae & Monocotiledônea \\
Cyperus rotundus & CYPRO & Cyperaceae & Monocotiledônea \\
Digitaria horizontalis & DIGHO & Poaceae & Monocotiledônea \\
Eleusine indica & ELEIN & Poaceae & Monocotiledônea \\
Emilia sonchifolia & EMISO & Asteraceae & Dicotiledônea \\
Indigofera hirsuta & INDHI & Fabaceae & Dicotiledônea \\
Ipomoea acuminata & IPOAC & Convolvulaceae & Dicotiledônea \\
Portulaca oleracea & POROL & Portulacaceae & Dicotiledônea \\
Sida cordifolia & SIDCO & Malvaceae & Dicotiledônea \\
\hline
\end{tabular}

A porcentagem de cobertura do solo da comunidade infestante (Tabela 2), foi em média de $70 \%$ (dado não transformado) a partir dos 28 dias após a semeadura (DAS), independente do cultivar de milho em convivência. Aos 42 DAS as parcelas experimentais encontravam-se $90 \%$ cobertas pela comunidade infestante e, a partir dos 70 DAS, es ta cobertura foi praticamente total $(100 \%)$. Em nenhuma das avaliações foi constatado efeito dos cultivares sobre a cobertura do solo.

TABELA 2. Porcentagem ${ }^{1}$ de cobert ura do solo proporcionada pela comunidade infestante, em função do cultivar de milho e no decorrer do período experimental. Média de 4 repetições. Jaboticabal, 1992/93.

\begin{tabular}{lcccc}
\hline & \multicolumn{4}{c}{ ÉPOCAS (DAS) } \\
\cline { 2 - 4 } CULTIVARES & $\mathbf{2 8}$ & $\mathbf{4 2}$ & $\mathbf{7 0}$ & $\mathbf{1 5 0}$ \\
\cline { 2 - 4 } VF-7 & 54,90 & 76,90 & 90,00 & 83,30 \\
CD & 53,40 & 69,60 & 86,80 & 83,30 \\
PIR & 61,10 & 78,70 & 90,00 & 83,50 \\
VD-8 & 51,80 & 76,80 & 86,80 & 81,50 \\
ARQ & 56,80 & 80,10 & 90,00 & 85,50 \\
CARG & 55,60 & 79,70 & 90,00 & 75,70 \\
CF & 58,50 & 74,60 & 90,00 & 75,70 \\
F Trat. & $0,83 \mathrm{~ns}$ & $0,64 \mathrm{~ns}$ & $1,00 \mathrm{~ns}$ & $1,82 \mathrm{~ns}$ \\
CV $(\%)$ & 12,21 & 11,93 & 3,54 & 7,18 \\
DMS & 16,00 & 21,30 & 7,40 & 13,60 \\
\hline
\end{tabular}

1 - Dados transformado para arc sen $\sqrt{ } \times(\%)$

ns - não significativo $\mathrm{p} \epsilon$, teste $\mathrm{F}$ até $5 \%$ de probabilidade. 
As espécies de plantas daninhas da comunidade infestante foram agrupadas em três classes: monocotiledôneas, dicotiledôneas e totais. $\mathrm{Na}$ Tabela 3 encontram-se os dados referentes a densidade destas classes em função do cultivar de milho plantado e no decorrer do período experimental. Não se observou, em nenhuma das épocas de avaliação, efeito do cultivar de milho sobre a densidade destas classes. Em todos os cultivares de milho testados, observou-se que tanto a densidade de plantas daninhas monocotiledôneas quanto a de dicotiledôneas e, consequentemente, de totais, foi máxima ao redor dos 14 DAS, indicando que a partir desta época a comunidade infestante, independente da classe, encontrava-se plenamente estabelecida nas parcelas experimentais. Embora houvesse predominância no número de espécies de plantas daninhas dicotiledôneas constituindo a comunidade infestante, a densidade destas mostrou-se $45 \%$ menor que a de monocotiledôneas, independente do cultivar de milho e da época avaliada. Quando se considerou o cultivar e a época, observou-se que esta relação decresceu para $27 \%$ no cultivares CD e PIR aos 154 DAS, revelando supremacia das monocotiledôneas infestando estes cultivares no final do ciclo da cultura.

Tabela 3. Densidade (plantas $/ \mathrm{m}^{2}$ ) de plantas daninhas monocotiledôneas (M), dicotile dôneas (D) e tota is ( $\mathrm{T})$ existentes nas parcelas referentes aos cultivares, no decorrer do período experime ntal. Média de 4 repetições. Jaboticabal, 1992/93.

\begin{tabular}{|c|c|c|c|c|c|c|c|c|c|}
\hline \multirow[b]{2}{*}{ Cultivares } & \multicolumn{3}{|c|}{ 14 DAS } & \multicolumn{3}{|c|}{28 DAS } & \multicolumn{3}{|c|}{42 DAS } \\
\hline & M & D & $\mathbf{T}$ & M & D & $T$ & M & D & $T$ \\
\hline VF-7 & 14.1 & 7.2 & 16.0 & 14.3 & 6.9 & 15.9 & 14.3 & 6.4 & 15.6 \\
\hline$C D$ & 13.6 & 6.5 & 15.3 & 12.9 & 6.6 & 14.6 & 12.0 & 6.7 & 13.8 \\
\hline PIR & 13.9 & 7.3 & 15.7 & 13.8 & 7.4 & 15.6 & 12.1 & 7.0 & 13.9 \\
\hline VD-8 & 11.5 & 6.1 & 13.0 & 11.3 & 7.2 & 13.4 & 11.3 & 7.1 & 13.4 \\
\hline ARQ & 13.2 & 6.1 & 14.6 & 12.1 & 6.4 & 13.7 & 12.1 & 7.1 & 14.0 \\
\hline CARG & 13.6 & 7.2 & 15.4 & 13.4 & 7.6 & 15.6 & 13.4 & 7.2 & 15.2 \\
\hline $\mathrm{CF}$ & 15.2 & 6.3 & 16.9 & 14.7 & 7.1 & 16.4 & 14.2 & 6.8 & 15.7 \\
\hline F/Trat. & $\overline{1} . \overline{0} \overline{\mathrm{ns}}$ & $0.63 \mathrm{~ns}$ & $\overline{1.17} \overline{\mathrm{ns}}$ & $\overline{1} . \overline{\mathrm{lns}}$ & $\overline{0} . \overline{4} \overline{9} \mathrm{~ns}$ & $1.21 \mathrm{~ns}$ & $1.65 \mathrm{~ns}$ & $0 . \overline{53} \mathrm{~ns}$ & $\overline{1} . \overline{2} \overline{\mathrm{ns}}$ \\
\hline $\operatorname{cv}(\%)$ & 17.8 & 20.9 & 14.6 & 17.0 & 17.0 & 13.6 & 14.4 & 10.7 & 12.2 \\
\hline \multirow[t]{2}{*}{$\mathrm{dms}$} & 5.7 & 3.3 & 5.2 & 5.1 & 2.8 & 4.8 & 4.3 & 1.7 & 4.1 \\
\hline & \multicolumn{3}{|c|}{56 DAS } & \multicolumn{3}{|c|}{70 DAS } & \multicolumn{3}{|c|}{154 DAS } \\
\hline Cultivares & $\mathbf{M}$ & D & $\mathbf{T}$ & $\mathbf{M}$ & D & $\mathbf{T}$ & $\mathbf{M}$ & D & $\mathbf{T}$ \\
\hline VF-7 & 12.0 & 6.1 & 12.6 & 8.6 & 4.3 & 9.7 & 6.2 & 3.0 & 7.0 \\
\hline $\mathrm{CD}$ & 9.8 & 5.4 & 11.3 & 6.7 & 5.2 & 8.5 & 5.6 & 4.0 & 7.2 \\
\hline PIR & 11.7 & 5.8 & 13.1 & 8.3 & 4.4 & 9.4 & 5.9 & 4.4 & 7.2 \\
\hline VD-8 & 11.2 & 5.6 & 12.5 & 7.6 & 4.9 & 9.0 & 7.2 & 3.8 & 8.5 \\
\hline ARQ & 10.2 & 6.0 & 11.9 & 7.4 & 4.4 & 8.6 & 6.6 & 3.5 & 7.5 \\
\hline CARG & 9.0 & 5.2 & 10.4 & 8.4 & 4.3 & 9.5 & 6.8 & 3.0 & 7.4 \\
\hline CF & 10.6 & 5.7 & 12.1 & 8.1 & 4.7 & 9.4. & 7.4 & 3.8 & 8.3 \\
\hline F/Trat. & $0 . \overline{9} 0 \mathrm{~ns}$ & $0.59 \mathrm{~ns}$ & $1.03 \mathrm{~ns}$ & $\overline{1} . \overline{8} \mathrm{lns}$ & $0 . \overline{8} 9 \mathrm{~ns}$ & $1.19 \mathrm{~ns}$ & $\overline{1} . \overline{2} \overline{\mathrm{ns}}$ & $\overline{0} . \overline{6} 1 \mathrm{~ns}$ & $1 . \overline{1} \overline{\mathrm{ns}}$ \\
\hline $\operatorname{cv}(\%)$ & 18.4 & 15.5 & 14.7 & 12.7 & 16.1 & 8.9 & 18.2 & 25.8 & 14.7 \\
\hline $\mathrm{dms}$ & 4.5 & 2.1 & 4.1 & 2.3 & 1.7 & 1.9 & 2.8 & 3.0 & 2.6 \\
\hline
\end{tabular}


Uma vez que não se constatou efeito de cultivares sobre a densidade de plantas daninhas, os resultados referentes aos cultivares foram agrupados dentro de cada época de avaliação, permitindo, assim, a representação gráfica do comportamento da densidade das plantas daninhas ao longo do ciclo da cultura, conforme consta da Figura 1. Nesta pode-se observar que a comunidade infestante encontrava-se estabelecida aos 14 DAS, com cerca de 225 plantas $/ \mathrm{m}^{2}$, representando uma infestação de 2,25 milhões de plantas/ha. Esta infestação permane ceu praticamente constante até os 42 DAS, quando, então decresceu exponencialmente até a colheita-do milho (154 DAS), resultando em uma densidade final de aproximadamente 50 plantas $/ \mathrm{m}^{2}(500 \mathrm{mil}$ plantas/ha). Nesta ocasião, embora a densidade de plantas daninhas te nha se reduzido a $20 \%$ da inicial, o acúmulo de matéria seca destas era de aproximadamente $425 \mathrm{~g} / \mathrm{m}^{2}$ (4,25 t/ha).

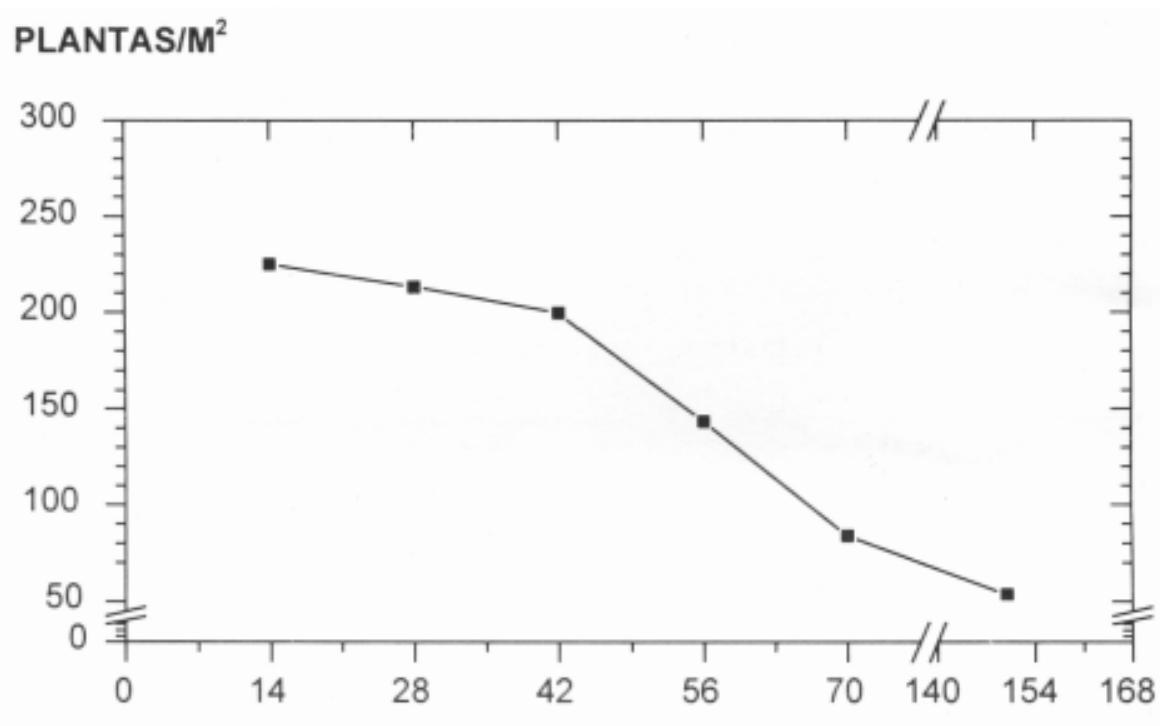

DIAS APÓS SEMEADURA

FIGURA 1. Densidade total de plantas daninhas ao longo do ciclo da cultura do milho, independente do cultivar plantado. Média de 28 repetições.

Quando se avaliou o peso da matéria seca da parte aérea das plantas daninhas mono e dicotile dôneas que conviviam com os sete cultivares de milho aos 150 DAS (Figura 2), observou-se que este foi muito superior nas monocotiledôneas, representand o $89 \%$ do peso total da comunidade infestante, independente do cultivar de milho com que estas conviviam. Embora o peso da matéria seca da comunidade infestante mostrasse uma tendência de ser menor quando em convivência com os cultivares de milho VF-7, CARG e CF, não se constatou efeito de cultivares sobre o peso da matéria seca da parte aérea tanto das mocotiled oneas como das dicotiledôneas, conforme pode ser constatado pelos valores de DMS encontrados. Os elevados valores de coeficiente de variação determinados para o peso da matéria seca de monstram que as plantas daninhas componentes da comunida de infestan te encontravam-se em diferentes estágios de crescimento, principalmente as dicotiledôneas. 


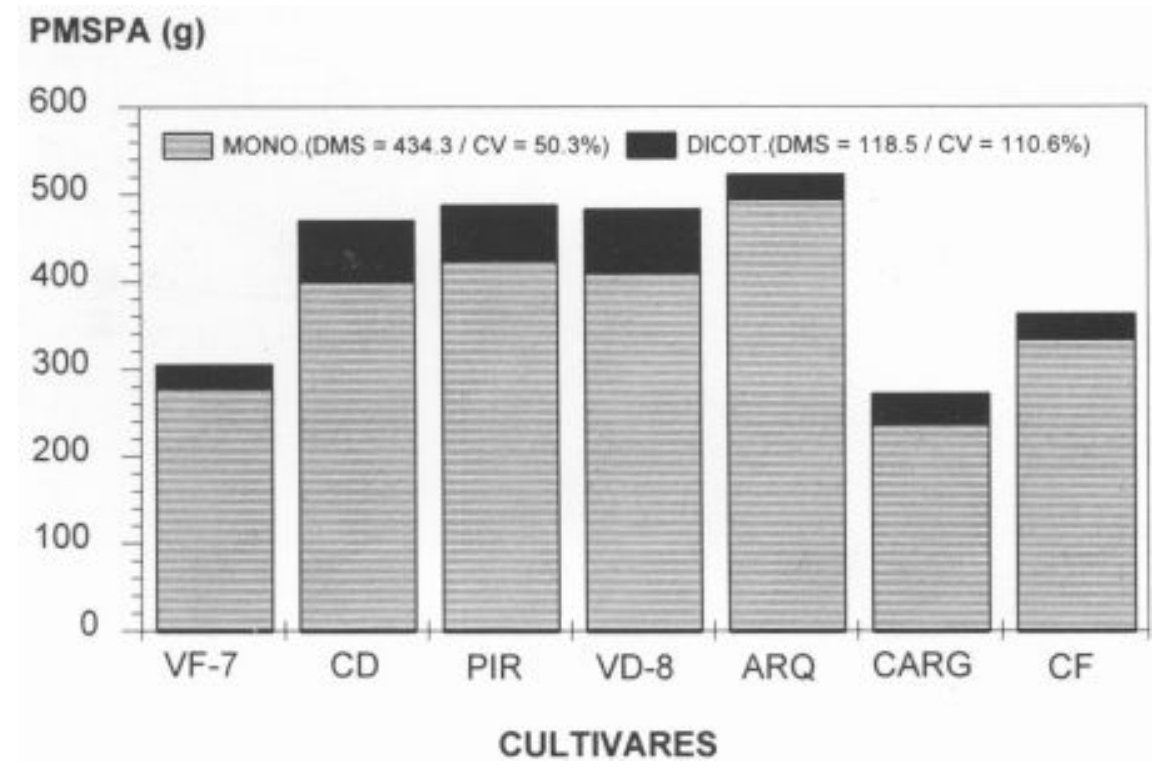

FIGURA 2. Peso da matéria seca da parte aérea das plantas daninhas mono e dicotiledóneas infestando sete cultivares de milho aos 150 dias.

As análises estatísticas dos parâmetros relacionados ao desenvolvimento da cultura não indicaram interações significativas entre os fatores cultivares e in te rf erência. Sendo as sim, a interferência da comunidade infestante sobre o desenvolvimento da cultura do milho, independente do cultivar analisado, ou seja, o fator interferência isoladamente, encontra-se representada na Figura 3. A barra de erro em cada época de avaliação corresponde a comparação das médias de com e sem interferência obtidas pelo teste de Tukey a $5 \%$ de probabilidade.

A interferência da comunidade infestante sobre a altura das plantas de milho manifestou-se, significativamente, já aos 35 DAS (Figura 3A), sendo que a partir dos 42 dias esta interferência reduziu, em média, $10 \%$ a altura das plantas. $\mathrm{Na}$ Tabela 4, pode-se observar que aos 7 DAS o cultivar VD-8 foi o que apresentou maior altura, independente da interferência da comunidade infestante. Aos 21 DAS todos os cultivares apresentavam mesma altura. Mas, a partir dos 35 DAS, os cultivares PIR e ARQ passaram a apresentar uma altura menor que os demais cultivares, resultado este que se manteve até os 84 DAS, quando os cultivares CD e CF apresentaram-se mais altos, seguidos pelos cultivares VD-8, CARG e VF-7. Pelos resultados, pode-se constatar que os cultivares VF-7 e PIR cresceram em altura até os 63 DAS, enquanto os demais cultivares continuaram a crescer até os 84 DAS, principalmente o CD e CF.

Quanto a área foliar das plantas de milho (Figura 3B), pode-se observar que a interferência da comunidade infestante manifestou-se significativamente a partir dos 35 DAS, chegando aos 84 DAS com uma redução de $17 \%$. Observouse aos 7 DAS que o cultivar CARG (Tabela 4), apres entou maior área foliar que os demais. Aos 21 DAS, embora este cultivar apresentas se tendência de maior área foliar, não se constatou diferenças entre os cultivares, o mesmo acontecendo aos 49 e 84 DAS. Mas aos 35 DAS, o cultivar CARG tinha maior área foliar que os cultivares PIR e ARQ, enquanto aos 63 DAS os cultivares VD-8 e VF-7, apresentaram menor área foliar. Pode-se observar que a área foliar de todos os cultivares foi máxima a os 63 DAS, independente da interferência das plantas daninhas. 

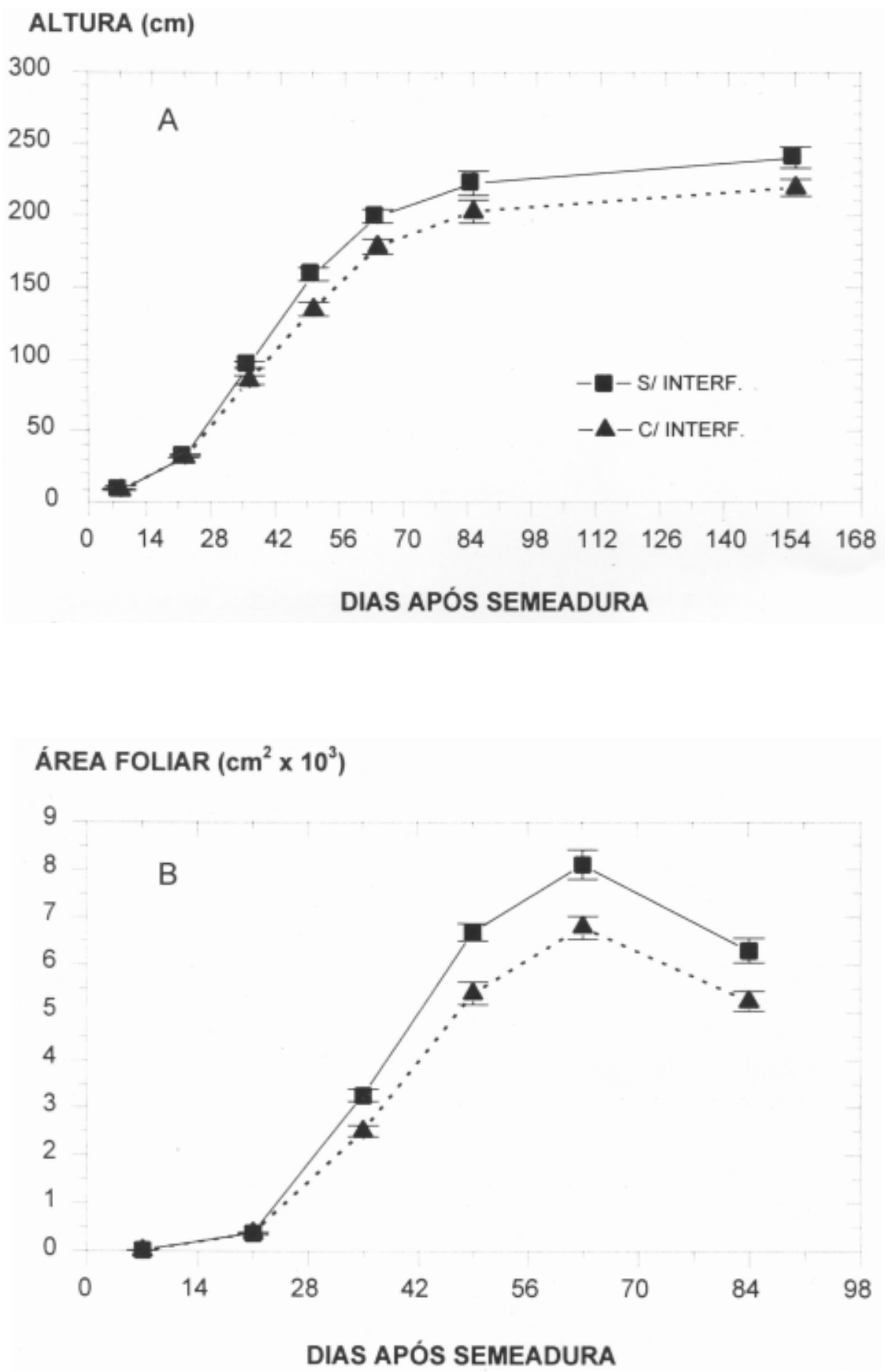

FIGURA 3. Efeito da interferência da comunidade infestante sobre a altura (A) e área foliar (B) da planta de milho, independentemente de seu cultivar. Média de 28 repetições. 
TABELA 4. Altura das plantas e área foliar de sete cultivares de milhõ, independente da interferência da comunidade infestante, Jaboticabal, 1993.

\begin{tabular}{|c|c|c|c|c|c|c|}
\hline \multirow[b]{2}{*}{ CULTIVARES } & \multicolumn{6}{|c|}{ ÉPOCAS (DAS) } \\
\hline & 7 & 21 & 35 & 49 & 63 & 84 \\
\hline & \multicolumn{6}{|c|}{ Altura da planta (cm) } \\
\hline VF -7 & 7,90ab & $30,60 \mathrm{a}$ & $89,70 \mathrm{a}$ & $153,80 \mathrm{a}$ & $203,90 \mathrm{a}$ & $201,50 \mathrm{bc}$ \\
\hline C.D. & $8,10 \mathrm{ab}$ & $30,00 \mathrm{a}$ & $94,90 \mathrm{a}$ & $172,30 \mathrm{a}$ & $205,90 \mathrm{a}$ & $264,80 \mathrm{a}$ \\
\hline PIR. & $8,20 \mathrm{ab}$ & $29,80 \mathrm{a}$ & $73,50 \mathrm{~b}$ & $118,00 \mathrm{~b}$ & $154,80 \mathrm{~b}$ & $153,00 \mathrm{~d}$ \\
\hline VD-8 & $9,10 \mathrm{a}$ & $31,50 \mathrm{a}$ & $96,50 \mathrm{a}$ & $155,40 \mathrm{a}$ & $199,50 \mathrm{a}$ & $216,50 \mathrm{~b}$ \\
\hline ARQ. & $8,20 \mathrm{ab}$ & $30,50 \mathrm{a}$ & $85,60 \mathrm{ab}$ & $109,40 \mathrm{~b}$ & $154,10 \mathrm{~b}$ & $177,50 \mathrm{~cd}$ \\
\hline CARG. 105 & $8,90 \mathrm{ab}$ & $34,50 \mathrm{a}$ & $98,50 \mathrm{a}$ & $154,50 \mathrm{a}$ & $201,30 \mathrm{a}$ & $215,30 \mathrm{~b}$ \\
\hline C.F. & $7,30 \mathrm{~b}$ & $31,50 \mathrm{a}$ & $93,80 \mathrm{a}$ & $158,60 \mathrm{a}$ & $201,60 \mathrm{a}$ & $264,80 \mathrm{a}$ \\
\hline F Cultivar (C) & $2, \overline{7} 6^{*}$ & $1,25 \mathrm{~ns}$ & $8,47^{* *}$ & $18,44 * *$ & $15,60 * *$ & $29,90 * *$ \\
\hline F Competição (CO) & $0,14 \mathrm{~ns}$ & $0,63 \mathrm{~ns}$ & $24,46^{* *}$ & $31,56 * *$ & $22,10^{* *}$ & $70,70 * *$ \\
\hline $\mathrm{C} \times \mathrm{CO}$ & $0,56 \mathrm{~ns}$ & $0,43 \mathrm{~ns}$ & $1,37 \mathrm{~ns}$ & $0,78 \mathrm{~ns}$ & $0,59 \mathrm{~ns}$ & $0,75 \mathrm{~ns}$ \\
\hline DMS C & 1,56 & 6,26 & 12,97 & 23,62 & 26,15 & 33,37 \\
\hline DMS CO & 0,55 & 2,18 & 4,51 & 8,22 & 9,10 & 11,62 \\
\hline \multirow[t]{2}{*}{ CV (\%) } & 12,25 & 12,91 & 9,24 & 10,42 & 8,91 & 10,07 \\
\hline & \multicolumn{6}{|c|}{ Área Foliar $\left(\mathrm{cm}^{2}\right)$} \\
\hline VF - 7 & $14,60 \mathrm{~b}$ & $334,40 \mathrm{a}$ & $2789,00 \mathrm{ab}$ & $5955,00 \mathrm{a}$ & $6135,00 \mathrm{c}$ & $5411,00 \mathrm{a}$ \\
\hline C.D. & $14,60 \mathrm{~b}$ & $348,60 \mathrm{a}$ & $2853,00 \mathrm{ab}$ & $6459,00 \mathrm{a}$ & $8210,00 \mathrm{ab}$ & $6332,00 \mathrm{a}$ \\
\hline PIR. & $13,90 \mathrm{~b}$ & $368,00 \mathrm{a}$ & $2641,00 \mathrm{~b}$ & $6385,00 \mathrm{a}$ & $7612,00 \mathrm{abc}$ & $5472,00 \mathrm{a}$ \\
\hline VD-8 & $14,50 \mathrm{~b}$ & $363,20 \mathrm{a}$ & $2872,00 \mathrm{ab}$ & $5954,00 \mathrm{a}$ & $6858,00 \mathrm{bc}$ & $5127,00 \mathrm{a}$ \\
\hline ARQ. & $13,90 \mathrm{~b}$ & $334,90 \mathrm{a}$ & . $2562,00 \mathrm{~b}$ & $5832,00 \mathrm{a}$ & $6891,00 \mathrm{abc}$ & $5875,00 \mathrm{a}$ \\
\hline CARG. 105 & $19,90 \mathrm{a}$ & $487,40 \mathrm{a}$ & $3595,00 \mathrm{a}$ & $6142,00 \mathrm{a}$ & $8280,00 \mathrm{ab}$ & $6362,00 \mathrm{a}$ \\
\hline C.F. & $16,70 \mathrm{ab}$ & $374,40 \mathrm{a}$ & $2809,00 \mathrm{ab}$ & $5562,00 \mathrm{a}$ & $8644,00 \mathrm{a}$ & $5868,00 \mathrm{a}$ \\
\hline F Cultivar (C) & $3,35 * *$ & $2,30 \mathrm{~ns}$ & $3,01^{* *}$ & $0,66 \mathrm{~ns}$ & $5,08^{* *}$ & $1,23 \mathrm{~ns}$ \\
\hline F Competição (CO) & $3,63 \mathrm{~ns}$ & $0,15 \mathrm{~ns}$ & $25,11^{* *}$ & $18,33^{* *}$ & $18,99 * *$ & $10,53^{* *}$ \\
\hline $\mathrm{CXCO}$ & $1,02 \mathrm{~ns}$ & $1,01 \mathrm{~ns}$ & $1,73 \mathrm{~ns}$ & $0,85 \mathrm{~ns}$ & $0,58 \mathrm{~ns}$ & $0,27 \mathrm{~ns}$ \\
\hline DMS C & 5,24 & 153,00 & 856,00 & 1692,00 & 1785,00 & 1861,00 \\
\hline DMS CO & 1,82 & 53,00 & 298,00 & 589,00 & 624,00 & 648,00 \\
\hline CV $(\%)$ & 21,82 & 26,43 & 19,16 & 18,02 & 15,29 & 20,72 \\
\hline
\end{tabular}

Com relação ao peso de matéria seca das fol has das plantas de milho (Figura 4A), verificou-se que a interferência da comunidade infestante manifestou-se a partir dos 35 DAS, sendo que esta interferência reduziu em até $26 \%$ o pe so da biomassa seca. Aos 7 DAS o cultivar CARG foi o quer apresentou maior peso de matéria seca de folhas (Tabela 5). Contudo, aos 21 DAS, os demais cultivares igualaram ao CARG, à exceção do VD-8 e ARQ que tinham menor peso de matéria seca das folhas. Dos 35 aos 84 DAS não mais se constatou diferenças entre os cultivares. Na última avaliação, os cultivares CD e CF tinham maior peso de biomassa seca das folhas que os cultivares VF-7, VD-8 e ARQ. Os resultados demonstram que o acúmulo de matéria seca nas folhas dos cultivares PIR, VD-8 e CARG foi máxi ma aos 63 DAS, enquanto no VF-7 e ARQ foi aos 84 DAS e no CD e CF foi aos 105 DAS, inde pendente da interferência das plantas daninhas. 

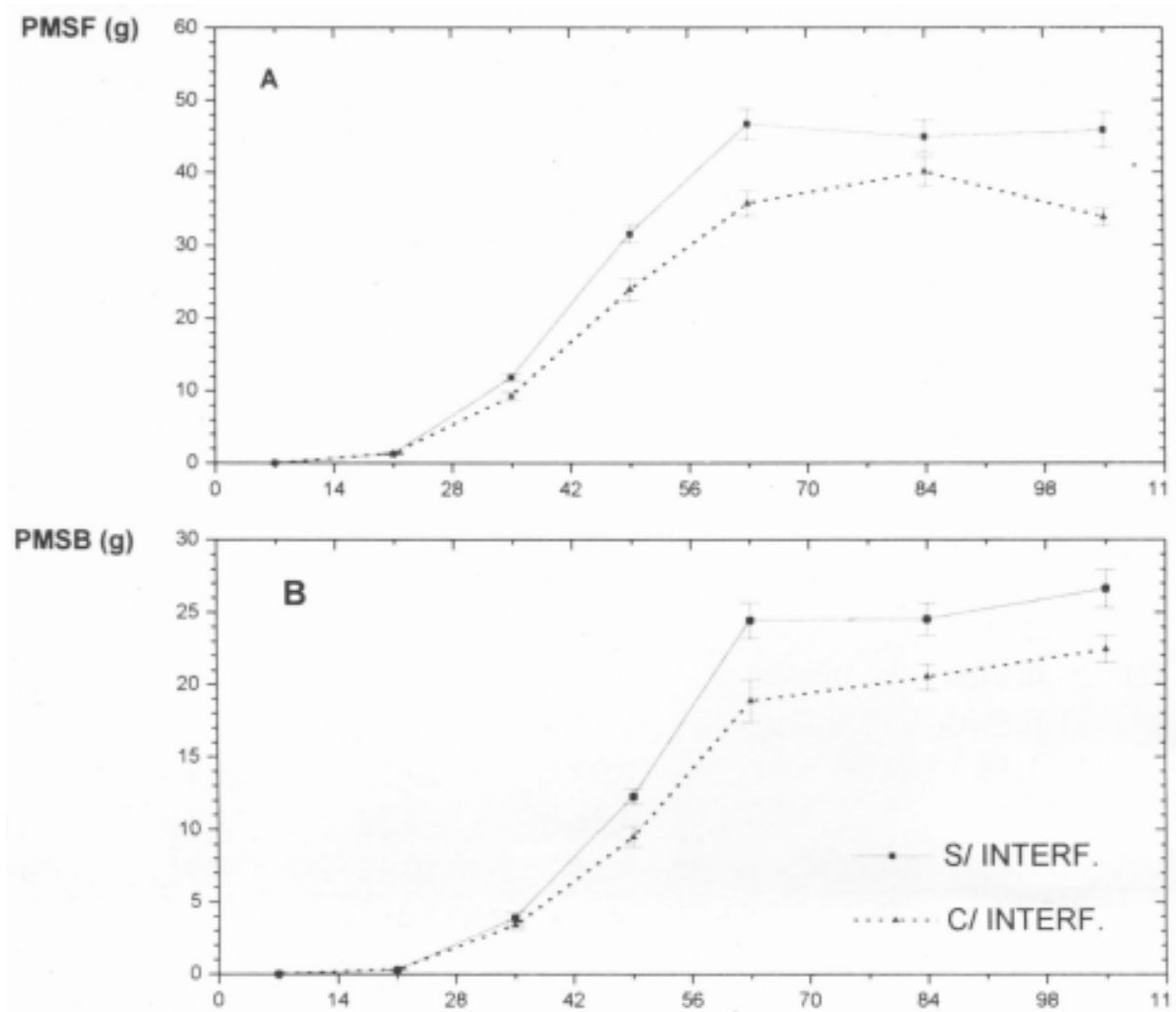

$\operatorname{PMSC}(\mathbf{g})$

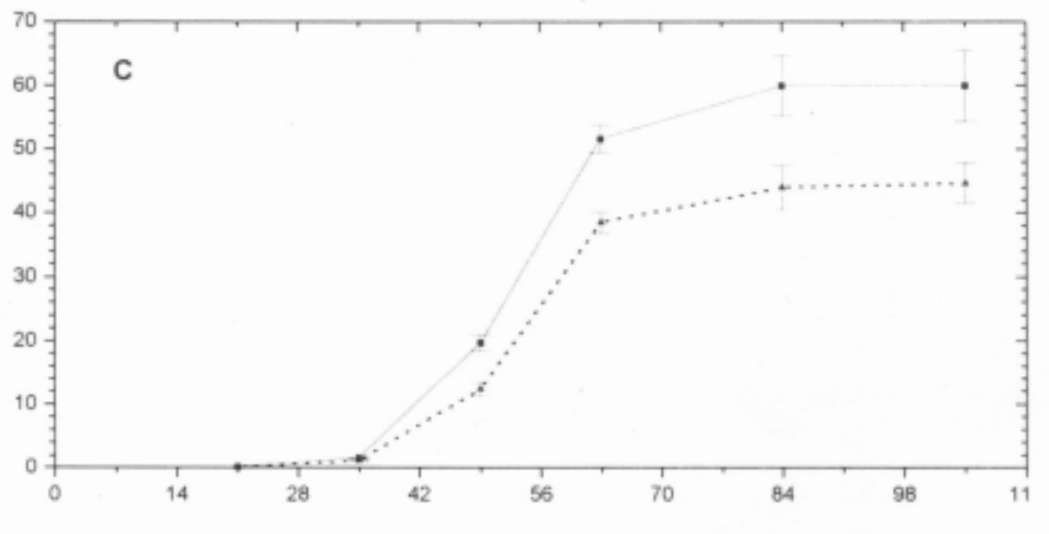

DIAS APÓS SEMEADURA

FIGURA 4. Efeito da comunidade infestante sobre o peso da matéria seca de folhas (A), bainhas (B) e colmo (C) da planta de milho, independentemente de seu cultivar. Média de 28 repetições.

Para o peso de biomassa seca de bainhas (Figura 4B), a comunidade infestante passou a interferir negativamente, a partir dos 49 DAS, provocando reduções da ordem de $23 \%$. Não se constatou diferença entre os cultivares até os 63 DAS (Tabela 5). A partir dos 84 DAS, os cultivares CD e CF tinham maior peso que o VF7 e VD-8, enquanto os de mais cultivares apresentaram valores interme diários. $\mathrm{O}$ acúmulo de biomassa seca nas bainhas foi máximo aos 63 Das para os cultivares VF-7, PIR, VD-8 e CARG, enquanto para $\mathrm{CD}$, ARQ e CF foi aos 105 DAS. 
Interferência das plantas daninhas sobre algumas características agronômicas $e$ a produtividade de sete cultivares de milho.

TABELA 5. Peso da biomassa seca de folhas, bainhas e colmos de sete cultivares de milho, independente da interferência da comunidade infestante, Jaboticabal, 1992/93.

\begin{tabular}{|c|c|c|c|c|c|c|c|}
\hline \multirow[b]{2}{*}{ CULTIVARES } & \multicolumn{7}{|c|}{ ÉPOCAS (DAS) } \\
\hline & 7 & 21 & 35 & 49 & 63 & 84 & 105 \\
\hline & \multicolumn{7}{|c|}{ Peso de Biomassa Seca de Folhas (g) } \\
\hline VF -7 & $0,04 \mathrm{~b}$ & $1,21 \mathrm{ab}$ & $10,70 \mathrm{a}$ & $30,07 \mathrm{a}$ & $41,31 \mathrm{a}$ & $43,49 \mathrm{a}$ & $33,46 \mathrm{~b}$ \\
\hline C.D. & $0,04 \mathrm{~b}$ & $1,21 \mathrm{ab}$ & $10,18 \mathrm{a}$ & $30,02 \mathrm{a}$ & $49,17 \mathrm{a}$ & $49,42 \mathrm{a}$ & $49,52 \mathrm{a}$ \\
\hline PIR. & $0,04 \mathrm{~b}$ & $1,26 \mathrm{ab}$ & $10,12 \mathrm{a}$ & $30,87 \mathrm{a}$ & $46,54 \mathrm{a}$ & $39,90 \mathrm{a}$ & $40,92 b$ \\
\hline VD-8 & $0,04 \mathrm{~b}$ & $1,16 \mathrm{~b}$ & $10,17 \mathrm{a}$ & $27,48 \mathrm{a}$ & $41,57 \mathrm{a}$ & $35,47 \mathrm{a}$ & $32,76 \mathrm{~b}$ \\
\hline ARQ. & $0,03 \mathrm{~b}$ & $1,11 \mathrm{~b}$ & $9,28 \mathrm{a}$ & $21,83 \mathrm{a}$ & $31,87 \mathrm{a}$ & $41,44 \mathrm{a}$ & $34,06 \mathrm{~b}$ \\
\hline CARG. 105 & $0,06 \mathrm{a}$ & $1,78 \mathrm{a}$ & $12,44 \mathrm{a}$ & $26,72 \mathrm{a}$ & $49,98 \mathrm{a}$ & $44,71 \mathrm{a}$ & $38,88 \mathrm{ab}$ \\
\hline C.F. & $0,04 \mathrm{~b}$ & $1,33 \mathrm{ab}$ & $10,91 \mathrm{a}$ & $26,81 \mathrm{a}$ & $47,64 \mathrm{a}$ & $43,95 \mathrm{a}$ & $49,48 \mathrm{a}$ \\
\hline F Cultivar $(\bar{C})$ & $\overline{6}, \overline{6} \overline{9}^{* *}-\overline{-}$ & $2,88^{*}$ & $\overline{0}, \overline{9} \overline{2 n s}$ & $1,60 \mathrm{~ns}$ & $-\overline{1}, \overline{58 \mathrm{~ns}}$ & $\overline{1,19}-\overline{\mathrm{ns}}$ & $\overline{7}, \overline{08 * *}$ \\
\hline F Competição (CO) & $0,00 \mathrm{~ns}$ & $0,54 \mathrm{~ns}$ & $11,22 * *$ & $17,06^{* *}$ & $25,19^{* *}$ & $2,62 \mathrm{~ns}$ & $34,58^{* *}$ \\
\hline $\mathrm{CXCO}$ & $0,74 \mathrm{~ns}$ & $0,84 \mathrm{~ns}$ & $0,86 \mathrm{~ns}$ & $1,08 \mathrm{~ns}$ & $0,34 \mathrm{~ns}$ & $1,20 \mathrm{~ns}$ & $2,56^{*}$ \\
\hline DMS C & 0,015 & 0,58 & 4,50 & 10,72 & 15,26 & 17,47 & 11,94 \\
\hline DMS CO & 0,01 & 0,20 & 1,56 & 3,73 & 5,31 & 6,08 & 4,16 \\
\hline \multirow[t]{2}{*}{ CV $(\%)$} & 24,55 & 29,04 & 27,40 & 24,93 & 21,82 & 26,39 & 19,27 \\
\hline & \multicolumn{7}{|c|}{ Peso de Biomassa Seca de Bainhas (g) } \\
\hline VF -7 & $0,01 \mathrm{a}$ & $0,31 \mathrm{a}$ & $3,04 \mathrm{a}$ & $11,53 \mathrm{a}$ & $26,94 \mathrm{a}$ & $20,25 b c$ & $20,77 \mathrm{~b}$ \\
\hline C.D. & $0,01 \mathrm{a}$ & $0,34 \mathrm{a}$ & $4,06 \mathrm{a}$ & $11,43 \mathrm{a}$ & $23,79 \mathrm{a}$ & $27,74 a$ & $29,37 \mathrm{a}$ \\
\hline PIR. & $0,01 \mathrm{a}$ & $0,32 \mathrm{a}$ & $3,96 \mathrm{a}$ & $12,32 \mathrm{a}$ & $25,16 \mathrm{a}$ & $21,74 a b c$ & $24,54 a b$ \\
\hline VD-8 & $0,01 \mathrm{a}$ & $0,29 \mathrm{a}$ & $3,38 \mathrm{a}$ & $11,29 \mathrm{a}$ & $23,13 \mathrm{a}$ & $17,79 \mathrm{c}$ & $19,08 \mathrm{~b}$ \\
\hline ARQ. & $0,01 \mathrm{a}$ & $0,29 \mathrm{a}$ & $3,35 \mathrm{a}$ & $8,45 \mathrm{a}$ & $22,70 \mathrm{a}$ & $23,22 \mathrm{abc}$ & $25,88 \mathrm{ab}$ \\
\hline CARG. 105 & $0,01 \mathrm{a}$ & $0,40 \mathrm{a}$ & $4,11 \mathrm{a}$ & $10,53 \mathrm{a}$ & $26,98 \mathrm{a}$ & $21,94 \mathrm{abc}$ & $23,22 \mathrm{ab}$ \\
\hline C.F. & $0,01 \mathrm{a}$ & $0,31 \mathrm{a}$ & $3,49 \mathrm{a}$ & $10,63 \mathrm{a}$ & $22,99 \mathrm{a}$ & $25,33 \mathrm{ab}$ & $29,60 \mathrm{a}$ \\
\hline F Cultivar $(\bar{C})$ & $\overline{0}, \overline{6} \overline{9} \overline{\mathrm{ns}}-\overline{-}$ & $1,08 \mathrm{~ns}$ & $\overline{0}, \overline{9} 2 \mathrm{~ns}$ & $1,10 \mathrm{~ns}$ & $0, \overline{48 n s}$ & $3,8 \overline{6}^{* *}$ & $\overline{6}, \overline{10} \bar{*}$ \\
\hline F Competição (CO) & $0,06 \mathrm{~ns}$ & $0,39 \mathrm{~ns}$ & $2,48 \mathrm{~ns}$ & $9,94 * *$ & $6,96^{* *}$ & $9,91^{* *}$ & $9,94^{* *}$ \\
\hline $\mathrm{C} \times \mathrm{CO}$ & $1,24 \mathrm{~ns}$ & $0,40 \mathrm{~ns}$ & $1,17 \mathrm{~ns}$ & $0,61 \mathrm{~ns}$ & $0,61 \mathrm{~ns}$ & $0,63 \mathrm{~ns}$ & $2,01 \mathrm{~ns}$ \\
\hline DMS C & 0,01 & 0,16 & 1,89 & 12,05 & 12,05 & 7,31 & 7,13 \\
\hline DMS CO & 0,00 & 0,05 & 0,66 & 1,79 & 4,20 & 2,54 & 2,48 \\
\hline \multirow[t]{2}{*}{$\mathrm{CV}(\%)$} & 80,57 & 32,09 & 33,65 & 30,45 & 31,49 & 20,84 & 18,63 \\
\hline & \multicolumn{7}{|c|}{ Peso de Biomassa Seca de Colmos (g) } \\
\hline VF -7 & --- & $0,04 \mathrm{~b}$ & $1,19 \mathrm{ab}$ & $16,28 \mathrm{ab}$ & $41,56 \mathrm{a}$ & $46,09 \mathrm{~b}$ & $41,78 \mathrm{~b}$ \\
\hline C.D. & --- & $0,06 \mathrm{ab}$ & $1,24 a b$ & $19,89 \mathrm{ab}$ & $49,17 \mathrm{a}$ & $80,68 \mathrm{a}$ & $84,84 a$ \\
\hline PIR. & --- & $0,04 \mathrm{~b}$ & $0,67 \mathrm{~b}$ & $13,68 \mathrm{ab}$ & $46,54 \mathrm{a}$ & $31,40 \mathrm{~b}$ & $35,11 \mathrm{~b}$ \\
\hline VD-8 & --- & $0,05 \mathrm{ab}$ & $1,44 \mathrm{ab}$ & $20,79 \mathrm{a}$ & $41,57 \mathrm{a}$ & $42,17 \mathrm{~b}$ & $43,08 \mathrm{~b}$ \\
\hline ARQ. & $--\cdot$ & $0,07 \mathrm{ab}$ & $0,84 \mathrm{~b}$ & $8,54 \mathrm{~b}$ & $38,86 \mathrm{a}$ & $41,55 b$ & $32,67 \mathrm{~b}$ \\
\hline CARG. 105 & $\cdots$ & $0,08 \mathrm{a}$ & $1,80 \mathrm{ab}$ & $16,06 \mathrm{ab}$ & $49,98 \mathrm{a}$ & $45,77 \mathrm{~b}$ & $50,72 b$ \\
\hline C.F. & -... & $0,06 \mathrm{ab}$ & $2,14 \mathrm{a}$ & $16,59 \mathrm{ab}$ & $47,57 \mathrm{a}$ & $76,25 \mathrm{a}$ & $78,25 \mathrm{a}$ \\
\hline F Cultivar $(\bar{C})$ & -- & $3, \overline{71^{* *}}$ & $\overline{3},\left.\overline{9}\right|^{* *}$ & $4,76^{* *}$ & $-\overline{1}, \overline{10}-\overline{\mathrm{ns}}$ & $\overline{16}, \overline{3} \overline{6}^{* *}$ & $\overline{2} 2, \overline{1} 1^{* *}$ \\
\hline F Competição (CO) & --- & $1,22 \mathrm{~ns}$ & $4,29^{*}$ & $26,58^{* *}$ & $24,81^{* *}$ & $20,85^{* *}$ & $20,83^{* *}$ \\
\hline $\mathrm{CXCO}$ & --- & $2,34^{*}$ & $0,20 \mathrm{~ns}$ & $1,73 \mathrm{~ns}$ & $0,35 \mathrm{~ns}$ & $2,04 \mathrm{~ns}$ & $2,82 \mathrm{~ns}$ \\
\hline DMS C & -- & 0,04 & 1,15 & 8,22 & 15,41 & 20,40 & 19,50 \\
\hline DMS CO & --. & 0,01 & 0,40 & 2,86 & 5,36 & 7,10 & 6,79 \\
\hline CV $(\%)$ & $\cdots$ & 39,46 & 55,65 & 33,01 & 22,02 & 25,25 & 23,98 \\
\hline
\end{tabular}


Quando verificamos a interferência da comunidade infestante sobre a biomassa seca do colmo das plantas de milho, observamos que ocorreu a partir dos 35 DAS, proporciona ndo reduções de até $39 \%$. 0 peso da biomassa seca dos colmos dos cultivares variou muito nas avaliações realizadas dos 21 aos 29 DAS, mas, de modo geral, este tendeu a ser menor nos cultivares PIR e ARQ (Tabela 5), Aos 63 DAS não se constatou dife rença entre os cultivares quanto a este parâmetro, mas, a partir de 84 DAS o peso da matéria seca de colmos dos cultivares $\mathrm{CD}$ e $\mathrm{CF}$ mostraram-se maiores que dos demais cultivares, que não deferiram en tre si. O acúmulo de biomassa seca nos colmos do cultivar PIR foi máximo aos 63 DAS, para os cultivares VF-7 e ARQ foi aos 84 DAS e para os demais foi aos 105 DAS.

Na Tabela 6, encontram-se os dados referentes a interferência da co mu ni da de infestante sobre algumas características agronômicas e produtivas de plantas de milho, independente dos - cultivares estudados. Nesta pode-se verificar que a interferência da comunidade infestante reduziu em 5\% a altura de inserção da primeira espiga; em 15 e 13\% o comprimento e a circunferência das espigas, respectivamente; em 23 e $28 \%$ os pesos da espigas e dos grãos e em $32 \%$ a produção estimada da cult ura, resultados semelhantes aos obtidos por Sales (1991) e Young et al. (1984). Os outros parâmetros avaliados: estande final, porcentagem de acamamento, número de espigas por planta, número de fileiras de grãos por espiga, comprimento da palha, compactação da palha e dano causado por Helicoverpa zea não foram afetados pela interferência da comu nidade infestante, por isso não constam desta tabela.

TABELA 6. Algumas características agronômicas e produtivas de sete cultivares de milho, e efeito da interferência da comunidade infestante sobre estas. Jaboticabal, 1993.

\begin{tabular}{|c|c|c|c|c|c|c|}
\hline & $\begin{array}{c}\text { Altura } \\
\text { espiga }(\mathrm{cm})\end{array}$ & $\begin{array}{c}\text { Compr. } \\
\text { espiga }(\mathrm{cm})\end{array}$ & $\begin{array}{c}\text { Circunf. } \\
\text { espiga }(\mathrm{cm})\end{array}$ & $\begin{array}{c}\text { Peso } \\
\text { espiga (g) }\end{array}$ & $\begin{array}{c}\text { Peso } \\
\text { grãos (g) }\end{array}$ & $\begin{array}{c}\text { Produção } \\
\text { Est. (kg/ha) }\end{array}$ \\
\hline & \multicolumn{6}{|c|}{ Cultivares } \\
\hline VF-7 & $114,60 \mathrm{c}$ & $14,40 \mathrm{bc}$ & $13,90 \mathrm{a}$ & $122,20 \mathrm{bc}$ & $87,30 \mathrm{ab}$ & $3875,70 \mathrm{bcd}$ \\
\hline $\mathrm{CD}$ & $174,50 \mathrm{a}$ & $14,50 \mathrm{bc}$ & $14,10 \mathrm{a}$ & $125,90 \mathrm{ab}$ & $70,60 \mathrm{~b}$ & $3336,60 \mathrm{bcd}$ \\
\hline PIR & $104,20 \mathrm{~cd}$ & $14,80 \mathrm{bc}$ & $13,90 \mathrm{a}$ & $122,20 b c$ & $81,60 \mathrm{ab}$ & $2942,40 \mathrm{~d}$ \\
\hline VD-8 & $129,10 b$ & $14,40 \mathrm{bc}$ & $14,40 \mathrm{a}$ & $128,50 \mathrm{ab}$ & $84,30 \mathrm{ab}$ & $4218,40 \mathrm{~b}$ \\
\hline ARQ & $98,40 \mathrm{~d}$ & $13,80 \mathrm{c}$ & $12,70 \mathrm{~b}$ & $99,50 \mathrm{c}$ & $68,70 \mathrm{~b}$ & $3129,70 \mathrm{~cd}$ \\
\hline CARG & $138,70 \mathrm{~b}$ & $16,20 \mathrm{a}$ & $13,90 \mathrm{a}$ & $149,10 \mathrm{a}$ & $103,90 \mathrm{a}$ & $5398,50 \mathrm{a}$ \\
\hline \multirow[t]{2}{*}{$\mathrm{CF}$} & $137,00 \mathrm{a}$ & $15,50 \mathrm{ab}$ & $13,70 \mathrm{a}$ & $136,00 \mathrm{ab}$ & $85,30 \mathrm{ab}$ & $3969,00 \mathrm{bc}$ \\
\hline & \multicolumn{6}{|c|}{ Interferência } \\
\hline $\mathrm{COM}$ & $129,50 \mathrm{~b}$ & $14,00 \mathrm{~b}$ & $13,50 \mathrm{~b}$ & $109,70 \mathrm{~b}$ & $69,80 \mathrm{~b}$ & $3113,40 \mathrm{~b}$ \\
\hline SEM & $136,90 \mathrm{a}$ & $15,60 \mathrm{a}$ & $14,10 \mathrm{a}$ & $142,70 \mathrm{a}$ & $96,40 \mathrm{a}$ & $4563,80 \mathrm{a}$ \\
\hline F cult $(\mathrm{C})$ & $97,97 * *$ & $8,46^{* *}$ & $11,85^{* *}$ & $6,76^{* *}$ & $5,27^{* *}$ & $14,19^{* *}$ \\
\hline Int (I) & $9,81^{* *}$ & $58,44 * *$ & $29,75^{* *}$ & $59,59 * *$ & $47,54^{* *}$ & $75,46^{* *}$ \\
\hline $\mathrm{C} \times \mathrm{I}$ & $0,69 \mathrm{~ns}$ & $0,86 \mathrm{~ns}$ & $0,54 \mathrm{~ns}$ & $0,69 \mathrm{~ns}$ & $0,68 \mathrm{~ns}$ & $1,43 \mathrm{~ns}$ \\
\hline CV (\%) & 6,60 & 5,40 & 13,10 & 13,00 & 17,30 & 16,27 \\
\hline DMS C & 13,70 & 1,20 & 0,70 & 25,60 & 22,40 & 970,80 \\
\hline DMS I & 4,80 & 0,40 & 0,20 & 8,90 & 7,80 & 337,90 \\
\hline
\end{tabular}


Se considerarmos as condições de interferência (com e sem) como fatores dependentes dos cultivares, desprezando-se a inexistência de interação entre eles, pode-se isolar o comportamento de cada cultivar dentro da condição de interferência. Para a produção estimada, considerada a característica agronômica de maior interesse, observou-se que, quando os cultivares não sofrera m interfe rência da comunidade infestante, esta foi maior no cultivar CARG, que não diferenciou dos cultivares VD-8 e CF. Os demais cultivares apresentaram uma produção decrescente na seguinte ordem: VF-7, CD, ARQ e PIR. A produção do PIR nestas condições, foi cerca de $47 \%$ menor que a do CARG (Tabela 7).

TABELA 7. Efe ito da interferência da comunidade infestante sobre a produção estimada de sete cultivares de milho. Jaboticabal, 1993.

\begin{tabular}{|c|c|c|c|}
\hline \multirow{3}{*}{ CULTIVARES } & \multicolumn{2}{|c|}{ PRODUÇÃO (kg\ha) } & \multirow{3}{*}{$\begin{array}{c}\text { REDUÇÃO } \\
(\%)\end{array}$} \\
\hline & Sem & Com & \\
\hline & Interferência & Interferência & \\
\hline VF-7 & $4297,00 \mathrm{bc}$ & $3454,00 \mathrm{ab}$ & 19,62 \\
\hline $\mathrm{CD}$ & $4162,00 \mathrm{bc}$ & $2512,00 \mathrm{~b}$ & 39,64 \\
\hline PIR & $3265,00 \mathrm{c}$ & $2620,00 \mathrm{~b}$ & 19,76 \\
\hline VD-8 & $4989,00 \mathrm{ab}$ & $3454,00 \mathrm{ab}$ & 30,83 \\
\hline ARQ & $4105,00 \mathrm{bc}$ & $2155,00 \mathrm{~b}$ & 47,50 \\
\hline CARG & $6138,00 \mathrm{a}$ & $4659,00 \mathrm{a}$ & 24,10 \\
\hline CF & $4995,00 \mathrm{ab}$ & $2943,00 \mathrm{~b}$ & 41,08 \\
\hline FTrat. & $8,65^{* *}$ & $8,74^{* *}$ & -- \\
\hline $\mathrm{CV}(\%)$ & 13,56 & 18,12 & -- \\
\hline DMS & 1446,00 & 1317,00 & --- \\
\hline
\end{tabular}

Analisando a produção dos cultivares sob a interferência das comunidades infestantes, verificou-se que esta manteve-se maior no cultivar CARG, que por sua vez não diferenciou dos cultivares VF-7 e VD-8. Os demais cultivares apresentaram produção significativamente menor (45\%, em média) que a do cultivar CARG.

A redução na produção dos cultivares em decorrência da interferência imposta pela comunidade infestante foi bem maior no cultivar ARQ que nos outros cultivares. Talvez este fato possa ser atribuído a tendência deste cultivar em apresentar porte baixo, menor área foliar e biomassa seca das folhas. Além disto, este cultivar apresenta outra característica genética marcante, ou seja, folhas eretas. Estes fatores favorecem a penetração da luz, contribuindo para um melhor desenvolvimento das plantas daninhas, o que pode ser confirmado pela maior biomasssa da comunidade infestante quando conviveu com este cultivar. Santos et al. (1987) e Mundstock (1977) constataram que cultivares de milho de porte mais baixo, permitiam um maior crescimento das plantas daninhas. Os autores atribuíram este fato a maior incidência de radiação solar. Marais (1985) e Beale (1986), observaram correlações negativas entre a produtividade de milho e a biomassa seca acumulada pela comunidade infestante. Os outros cultivares também ti veram uma redução na produção em decorrência da interferência, sendo eles, em ordem decrescente, os cultivares $\mathrm{CF}, \mathrm{CD}$, VD-8, CARG, PIR e VF-7.

Estes resultados demonstraram que o cultivar CARG foi o mais produtivo em qualquer situação e que o cultivar PIR embora tenha sido o menos produtivo, foi o que menos sentiu os efeitos da interferência, ssim como o VF-7, contrastando com os cultivares ARQ, CF e CD 
que se mostraram muito sensíveis a interferência. Ferreira (1982), trabalhando com oito variedades diferentes de milho também verificou que estes apresentavam diferenças na suscetibilidade em relação à interferência das plantas daninhas.

\section{LITERATURA CITADA}

\section{ASOCIACIÓN LATINOAMERICANO DE}

MALEZAS. Re co me nd ac io ne s so bre unificación de los sistemas de evaluacion en ensayos de control de malezas. ALAM, Bogotá, v.1, n.1, p.35-8, 1974.

BEALE, M.W. Fall panicum interference in corn (Zea mays). New Brunswick, 1986. In: Dissertation Abstracts Internacional Bulletin, Ann Arbor, v.46, n.7, p.2129B, 1986.

BLANCO, H.G., SANTOS, A.L. dos. Plantas daninhas predominantes em áreas cultivadas com milho no Estado de São Paulo. Biológico. São Paulo, v.54, p.1-7, 1988.

CARleton, A.E., FOOTE, A. Comparison of methods for estimating total leaf are a of barley plant. Crop Sci., Madison, v.5, p.603, 1975.

EGLEY, G.H., DUKE, S.O. Physiology of weed seed dormancy and germination. In: DUKE, S.O. (Ed.) Weed physiology: Reproduction and ecophysiology. Boca Raton: CRC Press, Inc., v.1, 1987. p.27-64.

HEEMST, H.D.G. The influe nce of weed competition on crop yield. Agric. Syst., Wageningem, v.18, n.2, p.81-83, 1986.

\section{FERREIRA, E.G. Influência da matocompetição sobre cultivares de milho. Jaboticabal,}

1982. 46p. (Trabalho apres entado a Faculdade de Ciências Agrárias e Veterinárias, UNESP, Campus de Jaboticabal para graduação em Agronomia).

FORD, G.T., PLEASANT, J.MT. Competitive abilities of six corn (Zea mays L.) Hybrids with four weed control practies. Weed Technol. Champaign, v.8, p.124-8, 1994.

KEELEY, P.E., THULLEN, R.J. Light requirements of yellow nutseage and light interception by crops. Weed Sci., Champaign, v.26, n.1, p.10-6, 1978.

MARAIS, J.N. Weed competition in maize with reference to peasant farming. Fort Hare Papers, Johannesburgh, v.8, n.1, p.63-82, 1985.

MUNDSTOCK, C.M. Milho: distribuição entrelinhas. Lavo ura arrozeira, Porto Alegre, v.30, n.229, p.28-9, 1977.

RAMOS, L.R.M. Efeito de períodos de con vivência da comunidade infestante sobre o crescimento, nutrição mineral e produtividade da cultura do milho (Zea mays L.). Jaboticabal, UNESP, 1992, 100 p. Dissertação (Doutorado em Agronomia).

SALES, J.C. Determinação dos períodos de interferência e integração de práticas culturais com herbicidas no controle de plantas daninhas na cultura do milho (Zea mays L.). Pi racicaba: De pto de Horticultura, USP, 1991, 161p. Dissertação (Doutorado em Agronomia).

SANTOS, J.A.C., ANDRADE, M.A., ANDRADE, L.A.B., ABREU, A.R. Influência de portes de cultivares, número de capinas e épocas de colheita sobre a 
Interferência das plantas daninhas sobre algumas caracteristicas agronômicas e a produtividade de sete cultivares de milho.

incidência de plantas daninhas e produção de grãos de milho. Pesqui. Agropecu. Bras., Brasília, v.22, n.5, p.501-3, 1987.

VISW AN ATH, H. We ed control and efficient use of fertilizer in mayse (Zea mays L.). Bangalore, Un. of Agricultural
Sci.,

YOUNG, F.L., WISE, D.L., JONES, R.J. Quackgrass (Agropyron repens; interference on corn. Weed Sci., Champaign, v.32, n.2, p.226-34, 1984. 